\title{
Evaluating Lexical Cohesion in Nigerian Newspaper Genres: Focus on the Editorials
}

\author{
Zubairu Malah (Corresponding author) \\ Dept of English, Faculty of Modern Languages and Communication, University Putra Malaysia, Malaysia \\ E-mail: zubayrmalah@yahoo.com \\ Helen Tan \\ Dept of English, Faculty of Modern Languages and Communication, University Putra Malaysia, Malaysia \\ E-mail: helen@upm.edu.my \\ Sabariah Md Rashid \\ Dept of English, Faculty of Modern Languages and Communication, University Putra Malaysia, Malaysia \\ E-mail: smrashid@upm.edu.my
}

Received: 06-07-2016

Published: 02-01-2017
Accepted: 24-09-2016

doi:10.7575/aiac.ijalel.v.6n.1p.240
Advance Access Published: November 2016

URL: http://dx.doi.org/10.7575/aiac.ijalel.v.6n.1p.240

\begin{abstract}
Applied linguists paying scholarly attention to newspaper genres have often argued that findings emerging from such studies would be of pedagogical significance because most of the newspaper genres share certain conventional features with school genres. Similarly, this study explored lexical cohesion in newspaper editorials, and it is understood that the findings could help learners in handling persuasive writings. The study sought to identify the dominant sources of lexical cohesion in the editorials, and also to examine how lexical cohesion is utilized to achieve coherence in the editorials. Drawing on Systemic Functional Linguistics (SFL), the study applied Eggins' (2004) model of lexical cohesion and analyzed 30 editorial texts of 20,354 words drawn from three major Nigerian newspapers: The Guardian, The Nation, and Vanguard. The analysis revealed 2, 685 ties across 849 sentences. The data demonstrated that the major types of lexical cohesion in the editorials include: repetition (49.5\%), expectancy relations (15. 8\%), class/subclass $(11 \%)$, and synonymy $(10.8 \%)$. It was further revealed that lexical cohesion devices, which formed into chains (586) and isolated ties (837), were utilized in building coherence in the editorial texts. It was finally shown how findings of the study could be beneficial in ESP, EAP, and EGP learning, especially in persuasive writings.
\end{abstract}

Keywords: Editorials, Lexical cohesion, Newspaper Genres, Nigerian Newspapers, School Genres

\section{Introduction}

Different discourse communities are known to be characteristically associated with different genres (Bhatia, 2013; Jones, 2012), a fact that implies that to function well in any discourse community is to be familiar with the genres associated with the community, and sometimes to be able to even bend or blend a genre without jeopardizing its discourse success. However, text-focused researchers have drawn attention to the relationships and overlaps that exist between genres, where certain conventional features cut across different text types (see Flowerdew, 2015; Bhatia, 2013). These relations and overlaps between genres allow successful transferability of knowledge from genre to genre without distorting the conventional norms. In the light of these similarities and overlaps between genres, discourse analysts who concern themselves with newspaper genres have observed that newspaper genres share certain conventional features with school genres, and that knowledge of newspaper genres would be significant towards enhancing ESP, EAP, and EGP learning and material development (see Yin, 2015; Bonyadi and Samuel, 2013; Bhatia, 2013; Maddalena \& Belmonte, 2011; Ansary and Babaii, 2005; So, 2005). Similarly, this study is an attempt to unravel the patterns of lexical cohesion, as a tool for achieving coherence, of the newspaper editorials, so that the findings could be utilized to enhance how learners and novice journalists could handle this genre and related school genres.

Moreover, despite the disagreement among text-focused researchers as to whether cohesion is any essential in textual communication, many researchers have still firmly posited that among the genre-sensitive features of texts is lexical cohesion, and that even if it is not considered necessary, its significance cannot be overemphasized (see, Gonzalez, 2011; Tanskanen, 2006, Taboada, 2004; Martin, 2001). Lexical cohesion refers to the linguistic resources that signal discourse relations which transcend grammatical relations (Martin, 2001; Halliday and Hasan, 1976). These resources are utilized by texts producers to signal relations between parts of texts so that the texts could hold together as single units. This category of resources is purely semantic because they enable texts receivers to find texts meaningful and not random collection of unrelated sentences or utterances. They are linguistic devices built on the surface of texts, and they act like threads woven to make the different parts of texts move together as semantic units. This meaning-making 
property is basically what distinguishes lexical cohesion from Harris' (1952) formal equivalences of the same textual environments, which could not account for meanings of texts (Widdowson, 2004; Beaugrande and Dressler, 1981). On this basis, discourse researchers have contended that Harris' attempt was to extend the scope of grammar and analyze 'language above the clause or sentence' (see, for example, Jones, 2012; Widdowson, 2004).

Nevertheless, the notion of cohesion in texts was invoked in Halliday and Hasan (1976), who assert that cohesion is a necessary and sufficient property for the coherence of texts. But some linguists argue that cohesion is not so significant for the coherence of texts. They contend that texts may have cohesion but lack coherence (pseudo-coherent texts), or even lack cohesion but have coherence (see, for example, Sanders and Maat, 2006; Enkvist, 1978; Widdowson, 1978; Brown and Yule, 1983). However, most texts analysts believe that although cohesion might not be a necessary property for the coherence of texts, it is arguable that most coherent texts naturally exhibit cohesion, and the longer a coherent text gets, the more likely is it to show cohesion (see, for example, Tanskanen, 2006; Halliday, 1994; Martin, 1992; Hasan, 1984). In an attempt to support her argument for the significance of cohesion in texts' coherence, for example, Tanskanen (2006) asserts that the utilization of cohesive devices in texts is a collaborative effort by both texts producers, who build them in texts, and the texts receivers, who decode them from texts. She opines that this is an instance of how communicators collaborate towards coherence in discourse.

Therefore, while taking the argument in favor of cohesion as an essential feature for texts' coherence as its point of departure, the present study focused on lexical cohesion in newspaper editorials. The study is timely because as far as the literature suggests (see 2.1 and 2.3 below), studies focusing on lexical cohesion in texts and those concerned with Nigerian newspaper genres have not yet explored lexical cohesion in the editorials. The study is propitious because it seeks to sensitize learners, teachers, and material developers on the patterns of lexical cohesion characteristic of newspaper editorials, which are persuasive and argumentative like the school argumentative essay. Therefore based on the fact earlier highlighted on the transferability of knowledge among related genres, learners could utilize the knowledge contributed by the findings of this study in writing argumentative essays (Bhatia, 2013; Khabbazi-Oskouei, 2013; So, 2005), especially because earlier studies on cohesive devices in students' writings (see Rahman, 2013; Mohamed-Sayidina, 2010; Liu and Braine, 2005; Castro, 2004) have reported that most students were deficient in handling cohesive devices, and that findings from the analysis of newspaper genres could help learners in writing school genres.

\subsection{Objectives of the Study}

1 to identify the types and frequencies of lexical cohesion in newspaper editorials

2 to examine how lexical cohesion is utilized to build coherence in newspaper editorials

\section{Theoretical Framework of the Study}

This study drew on Systemic Functional Linguistics (henceforth SFL), which has been a theory of language and discourse developed by M. A. K Halliday and his followers. Texts analysts often draw on SFL in conducting various investigations (Flowerdew, 2013; Kaplan and Grabe, 2002). The theory was purposely tailored for the analyses of texts, so that texts analysts could arrive at sensible and useful findings on both written and spoken data (Halliday, 1994). In developing SFL, Halliday had drawn on many influential scholars some of whom include Firth and Malinowski (Flowerdew, 2013; Bloor and Bloor, 2004; Kaplan and Grabe, 2002). The concept of system in SFL was derived from Firth's suggestion on the nature of the grammar of a language. The scholar suggests that the grammar of a language is polysystemic, made up of paradigmatic set of choices. Similarly, the SFL views language as composed of systems of choices from which language users choose in their attempts to make meanings. On the other hand, Malinowski's idea of context of situation also influenced Halliday's submission. Malinowski emphasizes how context determines meanings of utterances. Accordingly, the systemic linguists believe that the choices of linguistic forms made by language users are determined by the contexts. Another influence was the Prague School's functional approach to language, where the SFL focuses more on attention on instances of language in use. The systemic linguists give more emphasis to texts as products of authentic social interactions than abstract and invented passages (Eggins, 2004; Halliday, 1994).

Therefore, SFL is both semantic and functional. It is semantic and functional because it focusses on both meaning and use respectively. It focusses on both meaning and use because the theory is not only concerned with the formal properties of language but most importantly also how language users utilize linguistic forms from the language paradigms to construct meanings in real life interactions. The theory is also termed lexicogrammar for it considers lexis and grammar as working together in the construction of meanings (Flowerdew, 2013; Eggins, 2004). Because meaning and use are the most central concerns of SFL, discourse analysts have often found the theory applicable for different analyses. This is basically what distinguishes it from other theories of language, such as the Chomsky's Generative Grammar, which are more concerned with the formal properties of language than meanings or social aspects of language (Flowerdew, 2013; Widdowson, 2004). Consequently, while systemic linguists examine authentic texts, Chomskyans examine non-text fragments and invented examples. This is what makes Generative Grammar irrelevant for the study of discourse (Kaplan and Grabe, 2002).

According to SFL, meanings in texts are made according to three broad metafunctions of ideational, interpersonal, and textual. Ideational metafunction concerns how language users construe things - processes, participants, and circumstances - in the real world; Interpersonal metafunction concerns the relationships between communicators (texts producers and receivers); while Textual metafunction concerns the construction of texts, how they are held together, and 
their sources of texture. These metafunctions are related to the contexts of situations of language use but they freely combine in texts, and they do not constrain each other (Halliday and Matthissen, 2014; Flowerdew, 2013).

Accordingly, SFL provides a framework for a range of linguistic analyses. Discourse analysts apply the theory in studies focusing on cohesion, genre analyses, register analyses, information structuring, thematic structure, thematic patterns, and so on (Bloor and Bloor, 2004; Taboada, 2004; Kaplan and Grabe, 2002). Therefore, cohesion analyses, like the present study, are concerned with the textual metafunction in texts. The focus of these studies is the discourse relations that hold texts together and give them texture. These relations transcend grammatical relations because they establish connections beyond the units of grammar (Martin, 2001; Halliday and Hasan, 1976). Systemic linguists have proposed many models for the analyses of lexical cohesion (see, for example, Halliday and Matthiessen, 2014; Eggins, 2004; Martin, 1992; Hasan, 1984; Halliday and Hasan, 1976). This study employed Eggins' (2004) model because it is so detailed that learners would find much easier to understand. Eggins also redefines the controversial collocation and also avoids some lexical relations, such as near-synonymy and superordinate, which have been challenged by many discourse analysts. Generally, Eggin's model identifies eight lexical relations as follows:

(1) Co-hyponymy: where two or more lexical items used in a text are subordinate members of a common superordinate item. Examples from the data include: (1) Nigeria - (14) Cameroun - (18) Russia -all members of the superordinate item country in text VN-02. The presence of the superordinate item in the text is not a condition for this relation to hold (Halliday and Matthiessen, 2014; Halliday, 1994).

(2) Class/Sub-class: where two or more lexical items used in a text relate through sub-classification; the relation between a superordinate item and one or more subordinate member(s). Examples from the data include: (5) 2012 - (11) 2013 - (25) year in text GN-07.

(3) Contrast: This is where lexical items encode contrast relationships. While Eggins (2004) terms this lexical relation contrast, different models term it differently as antonymy (see, for example, Halliday and Hasan, 1976; Halliday and Matthiessen, 2014), opposition (see, for example, McCarthy, 1988; Gonzalez, 2010), or complex paraphrase (see Hoey, 1991). But Martin (1992) and Tanskanen (2006) also label it contrast. Examples from the analyses include: (5) inadequate - (6) enough, and (7) discouraged - (8) encouraged in text $\mathbf{N N}-\mathbf{0 8}$.

(4) Synonymy: this is when lexical items used in a text encode similar meanings. This relation is termed simple paraphrase in Hoey's (1991) model, and equivalence in Tanskanen (2006) and Taboada (2004). It is termed synonymy in Eggins (2004), and examples include: (8) rowdiness - (15) chaos, and (25) heart of the city - (31) city centres from GN-06.

(5) Repetition: when a lexical item is reiterated (or repeated) in a text. Most lexical cohesion models, except a few such as McCarthy (1988), include repetition as a lexical relation. Some lexical cohesion analysts, such as Hoey (1991) and Tanskanen (2006) even identified simple and complex repetitions. Examples include: (5) poisoned - (7) poison, and (19) eighteen years - (23) 18 years used in $\mathbf{V N}-10$.

(6) Meronymy: this is when lexical items used in a text relate as whole to part (or vice versa). Therefore, the lexical item encoding the whole-item and that/those encoding the part-item(s) must all be found in the text for this relation to hold. Examples from NN-02 in the data include: (1) Nigeria - (3) North East - (6) South East - (8) South South.

(7) Co-meronymy: this is when lexical items used in a text relate by being parts of a common whole. This lexical relation, unlike meronymy relation, remains constant even when the whole-item is not found in the text. The relation holds only between the part-items. Examples from GN-04 in the data include: (19) Ondo State - (22) Rivers State - (32) Anambra State as all parts of a common whole Nigeria.

(8) Expectancy Relations: this is the second category of lexical relations in this framework. It is close to Halliday and Hasan's (1976) collocation. It is close to collocation because the relation is also based on the cooccurrence tendency of lexical items. But it contrasts with collocation because Eggins has specified some conditions under which lexical items can enter into expectancy relations. The scholar specifies that expectancy relations operate between a nominal element or verbal element and:

i- $\quad$ its typical doer, for example, (1) begging - (5) physically challenged persons as used in GN09 of the corpus

ii- $\quad$ its typical sufferer, for example, (1) wanton killings - (3) women and children used in VN-01

iii- $\quad$ its typical location, for example, (3) students - (6) school as used in NN-01

\section{Review of Related Studies}

\subsection{Previous Studies of lexical Cohesion}

Lexical cohesion analysis remains one of the major fields of research among discourse analysts. It is the cohesive effect achieved through the use of related lexical items in different parts of texts (Halliday and Matthiessen, 2014; Bloor and Bloor, 2004). Texts of different registers and genres, both monologic and dialogic, spoken or written, are being explored and different patterns of cohesion are being reported. Hoey (1991) argues that to study lexical cohesion in texts is to study the greater part of the texts' cohesion. Therefore many frameworks have been proposed for the analyses of lexical cohesion in texts (see, for example, Halliday and Matthiessen, 2014; Gonzalez, 2010; Tanskanen, 2006; Taboada, 2004; Martin, 1992). Most of these frameworks were developed to suit the different data being investigated, and to avoid controversial terminologies such as collocation and near-synonymy found in Halliday and Hasan's (1976) model. For instance, some cohesion analysts, such as McCarthy (1988), who dealt with conversation data, thought 
Halliday and Hasan's model might not be suitable for their data. But most of the frameworks proposed, unless for terminological differences, analyze similar lexical relations in texts.

Drawing on the different frameworks of lexical cohesion analyses, some texts analysts concern themselves with written texts and others focus attention on spoken texts. In any case, the studies are geared towards unravelling how writers or speakers (or interlocutors) utilize lexical cohesion to achieve different characteristics of discourse. In their attempt to explore the relation between lexical cohesion and genre, Lewin, Fine, and Young (2001) examined lexical cohesion in the introduction and discussion sections of Social Science Research articles. The researchers reported that repetition and synonymy were the most dominant sources of lexical cohesion in their corpus. They suggested that texts of a single genre mostly exhibit the same cohesive patterns. Therefore, this study has pointed to the fact that texts of different genres could show different cohesive patterns. A study by Angermeyer (2002) focused on lexical cohesion in multilingual conversations. The study data were conversations of a trilingual family in Canada, who spoke English, French, and German. The research observed that lexical cohesion, in form of lexical insertions from other languages into the matrix language, contributed tremendously in the coherence and discourse structure of multilingual conversations. This study has therefore shown how lexical cohesion operates like codeswitching in enabling multilingual interlocutors to achieve coherence.

While Angermeyer (2002) was concerned with multilingual conversations, Taboada (2004) was concerned with English and Spanish conversations. Taboada's study focused on the discourse characteristics that held the dialogues together as they were interactively built by interlocutors. To analyze the data, Taboada drew on three frameworks of speech genres, rhetorical structure, and cohesion. On cohesion, the researcher reported that lexical cohesion was the most dominant source of cohesion in both English and Spanish conversations, and that repetition was the dominant type of lexical cohesion in the corpus. This was in agreement with Hoey's (1991) findings that lexical cohesion was the most dominant, and repetition was also the most dominant. But Taboada's findings conflicted with Hasan's (1984) claim that cohesive chains interaction is always the result of cohesive harmony that leads to coherence in texts. Taboada reported that although the conversations in her data were well coherent, the chains hardly interacted. She therefore suggested that perhaps different text types require different degrees of cohesive harmony.

While Taboada (2004) analyzed conversations, Hoey (2005) explored newspaper writing. The researcher focused on how lexical items were primed to impact on text organization and cohesion. He reported that certain lexical items in newspaper writing were always primed either positively to participate in cohesion, or negatively to avoid it. He claimed that words primed to participate in cohesion are also primed to participate in either chains or ties, and also for specific types of cohesion. Hoey observed that words such as army, planet, political, and year were typically primed for cohesive chains in newspaper writing, while words like blink, elusive, and asinine were negatively primed to avoid cohesion in newspaper writing. This is an interesting discovery and it could be useful to ESP learners. While Hoey (2005) focused on newspaper writing, Tanskanen (2006) focused on different text types: conversations, prepared speeches, mailing lists, and academic writings. Tanskanen's study examined how text producers and receivers interactively utilized lexical cohesive resources to collaborate towards coherence. She discovered that lexical cohesion, in both longer and shorter chains, contributed in the coherence of all the text types in the corpus. She observed that prepared speeches and mailing lists were the most cohesive, and academic writings were the least cohesive. The researcher also reported that lexical chains in all the texts of the corpus corresponded to topic segments. Therefore, Tanskanen's findings on the correspondence of lexical chains and topical segments agreed with Morris and Hirst (1991) discovery. Morris and Hirst also reported that lexical chains corresponded with topic segments in their data. Tanskanen's findings have also revealed how texts of different genres exhibit lexical cohesion.

Unlike Tanskanen (2006) where different text types were focused on, Gonzalez (2010) investigated lexical cohesion in telephone conversations. The researcher discovered that the dominant sources of lexical cohesion in telephone conversations were repetitions (52.6\%), associative cohesion (24\%), and inclusive relations (10.5\%). She also observed how interlocutors utilized repetition, synonymy, and inclusive relations as triggers for topic management and continuity strategies. Gonzalez's findings are therefore close to Tanskanen's (2006) and Morris and Hirst (1991) that lexical chains were related to topic continuity in texts. The findings by Gonzalez are also close to Taboada's (2004) findings that repetition was the most dominant lexical cohesion in English and Spanish conversations. Therefore, Gonzalez's study has revealed that telephone conversations are also lexically cohesive. Drawing on the same framework employed in analyzing telephone conversations in Gonzalez (2010), Gonzalez (2011) examined lexical cohesion in broadcast multiparty conversations. The researcher discovered that broadcast discussions have high incidence of lexical cohesion. She reported that the most frequent lexical cohesion in multiparty discussions were repetitions $(59 \%)$, associative cohesion $(24 \%)$, and inclusive relations $(8.2 \%)$. The researcher showed how interlocutors utilized lexical ties of repetition, synonymy, and opposition in achieving the genre-specific needs of such discussions like topic management strategies, turn-taking behaviors, and frame-evoking strategies. She added that interlocutors employed associative cohesion and inclusive relations in order to shift focus to different aspects of general topics in the discussions. Therefore, this study has further revealed the relation between lexical cohesion and the speech genre of broadcast conversations. Like in telephone conversations as reported by Gonzalez (2010), interlocutors in broadcast discussions have also been found utilizing lexical ties in topic management and continuity strategies. These studies have revealed the connection between lexical cohesion and speech genres of telephone conversations and multiparty conversations.

When Gonzalez (2011) was concerned with a spoken genre, Mirzapour and Ahmadi (2011) focused on a written genre. Mirzapour and Ahmadi's study focused on English and Persian research articles. They aimed at unravelling the patterns 
of lexical cohesion preferred in the data. The researchers reported that in both English and Persian research articles, the most dominant sources of lexical cohesion were repetition, collocation, and synonymy. That while English research articles tend to exhibit repetition and collocation, Persian research articles preferred repetition and synonymy. Therefore, in both English and Persian research articles, writer preferred repetition most. These findings are close to Lewin et al.'s (2001) on lexical cohesion in SSR research articles. It has been reviewed earlier that Lewin et al also discovered that repetition and synonymy were the most dominant lexical cohesion in SSR research articles. Like Mirzapour and Ahmadi (2011), Malah (2015) also explored lexical cohesion in academic discourse. Malah researched how lexical cohesion contributed to generic coherence in applied linguistics research articles abstracts. The researcher discovered that the major sources of lexical cohesion in the abstracts were repetition (54\%), collocation (14\%), and hyponymy (11\%). He also reported how lexical cohesion contributed the generic coherence of the abstracts. Therefore, Malah's findings are close to Mirzapour and Ahmadi's (2011) findings that repetition and collocation were the most dominant sources of lexical cohesion in English research articles. These studies have also shown how repetitions are mostly preferred as cohesive devices in both written and spoken texts.

At this juncture, it has been seen how previous lexical cohesion studies focused on texts of different registers and genres. It would also be understood that previous lexical cohesion analyses, as the literature suggests, have so far not explored the newspaper editorial texts. Therefore, the present study attempted to fill this research gap. Filling this research gap by the present study could add to the existing body of literature on lexical cohesion analyses. The study could also reveal some relations between lexical cohesion and newspaper editorial genre. Ultimately, findings of the study could go a long way in sensitizing ESP, EAP and EGP learners on patterns of lexical cohesion in newspaper editorials and also in other persuasive and argumentative writings.

\subsection{The Newspaper}

The newspaper belongs to the broad and multidisciplinary field of media discourse. Media discourse refers to the totality of how language is used to represent realities in the broadcast and printed media, from television to newspaper (O'keeffe, 2006). It is a distinct context of language use with distinct features (Baker and Ellece, 2011). Media discourses come in both spoken and written forms. More examples include: magazines, chat shows, radio phone-ins, and so on. These discourses often exhibit rich linguistic elements purposely tailored to influence the public (Hua, 2008; Talbot, 2007). The newspaper is therefore a media text. It acts as a rhetorical document that conveys the news of daily events in the community. There are many sections in the newspaper, and the language pattern employed in each section is adjusted to conform to the targeted purpose it is aimed to achieve (Fowler, 1991). Similarly, Bhatia (2013) contends that different types of genres are found in the newspaper. The scholar expatiates that the newspaper genres include: news reports, headlines, sports reports, letters to the editors, editorials, advertisements, fashion columns, weather reports, book reviews, and so on.

Each newspaper genre is meant to serve a distinct communicative purpose. Accordingly, the newspaper's rich language exhibits different patterns of lexis and syntactic devices (Conboy, 2010). This characteristic feature makes the newspaper a rich source of linguistic data (Bhatia, 2013). The richness in newspaper language ensues because in most of its genres, the newspaper adopts different preferences in style, stance, and substance. While some genres are more socially responsible and objective (such as the news reports), others are obviously interpretive, sensational, and subjective (such as advertisement and most editorials) (Bhatia, 2004).

\subsection{Previous Studies of Newspaper Editorials}

The newspaper editorials, also termed variously as comment, opinion, leading article, or we say (Reah, 2002; Fowler, 1991), are sections in newspapers anonymously written by the editors. These sections are quite radically different from the other sections of the paper. While other sections of the paper, for example, present news accurately and dispassionately, the editorials serve as voice of the newspaper institution by representing the opinions, analyses, and views of the newspaper house on various issues. It is mostly persuasive in nature because the editors persuade the readership to reason with them. A significant feature of this genre is how the editors utilize vast linguistic resources in enacting their discourses (Bhatia, 2013; Conboy, 2010; Hua, 2008).

Therefore, the linguistic complexity of the newspaper editorials has been drawing the attention of discourse analysts. For instance, Bolivar (1994) investigated the macro-structures of the editorial texts. The researcher reported that the newspaper editorials typically exhibited the three functional sentences (or turns): lead, follow, and valuate. Ansary and Babaii (2005) focused on the generic structure potential of the newspaper editorials. The researchers discovered four obligatory rhetorical elements as: Headline, Addressing an Issue, Argumentation, and Articulating a Position; and three optional rhetorical elements as: providing Background Information, Initiating an Argument, and Closure of Argument, typical in all editorials. This study has also unraveled more genre-specific features of the newspaper editorials.

While Ansary and Babaii (2005) examined editorials written by writers of the same language and culture (Americans), Ansary and Babaii (2009) explored the generic structure potentials of newspaper editorials written by writers of different languages and culture (Americans, Iranians, and Pakistanis) to see if there would be any significant differences or similarities between the two. The researchers discovered that the editorials showed no significant differences in terms of their elements of rhetorical structure. Therefore, Ansary and Babii (2009) to some extent reported similar findings with Ansary and Babii (2005), and it points to the fact that English newspaper editorials are mostly written in similar rhetorical forms irrespective of the languages or cultures of the writers. 
Maddalena and Belmonte (2011) cross-linguistically explored the levels of writer-reader interaction in Peninsular Spanish and American English newspaper editorials. The researchers anchored their assessment in the proportions of the use of nuclei and satellite rhetorical relations in the texts. They reported that the American English editorials were more writer-resposible than the Peninsular Spanish ones. The data demonstrated that while in English editorials the writers often justified, explain, exemplified, and reformulated their points for readers to comprehend and adhere to the thesis presented, writers of Peninsular Spanish editorials often used negligible ancillary rhetorical relations. In the face of these findings, the researchers concluded that the Peninsular Spanish editorials writers were less audience-sensitive compared to the American English writers. Similarly, Kuhi and Mojood (2014) were cross-linguistically concerned with metadiscourse resources in English and Persian newspaper editorials. The study sought to examine the impact of cultural factors and generic conventions on the use and distribution of metadiscourse resources within a single genre. The researchers claimed that although negligible differences were found between the two sets of data, great deal of similarities were observed in the use and distribution of metadiscourse elements in English and Persian editorials. Based on the findings of the study, the researchers suggested that genre conventions had mainly determined the writers' choice of metadiscourse. The analysis further revealed that interactional category and attitude markers were respectively the dominant metadiscourse category and sub-category in the data; and that metadiscourse had much influence on the construction of persuasion in the editorials.

Nevertheless, a few discourse analysts have also explored the Nigerian newspaper editorials. For instance, a study by Uche (2005) examined how private newspaper houses in Nigeria set agenda in the editorial columns. The researcher reported that the editorials were mostly written to criticize and condemn governmental and political issues. Uche's study revealed how the editorial columns were being utilized by the Nigerian newspapers in setting their agenda. Similar to Uche's study, Ekeanyanwu (2009) researched the contents of the Nigerian newspapers editorials. The study sought to analyze and classify the contents of the editorials. The researcher observed that the editorials mostly focused on and criticized socio-economic issues of the country. Therefore, previous studies of Nigerian newspaper genres have not analyzed lexical cohesion in editorials. And, considering this research niche, conducting the present study could be propitious. The study aimed to take care of the gap in literature on the analyses of newspaper editorials. Therefore, the focus of this study is to explore lexical cohesion in editorials of Nigerian newspapers.

\section{Methodology}

\subsection{Research Approach}

This study employed qualitative approach, and two levels of analyses were conducted. The study began by identifying the types and frequencies of lexical cohesion in the editorials. These have been represented in tables and figures. Secondly, the study examined how lexical cohesion was utilized to support the coherence of the editorial texts. This has been discussed and evidenced in the results and discussion section.

\subsection{Sampling}

The study utilized purposive sampling technique to select newspapers and the types of editorial texts for analyses. While selecting newspapers and editorials for analyses, the research employed homogeneous sampling. The sampling of newspapers was purposive because the study intentionally selected papers that could enable the pursuit of its objectives. This was consistent with Creswell (2012), Matthew and Rozz (2010), and Tavakoli (2012). The decision to select each of the papers was informed by its popularity, fame, high circulation rate, wide readership, and being a national daily. The type of purposive sampling employed in selecting editorials was also homogeneous because all the editorials sampled had similar characteristic features by being texts and not cartoons or images. Additionally, they were all editorials written on social issues. This was also consistent with Creswell (2012), Matthew and Rozz (2010) on purposive sampling techniques.

\subsection{The Newspapers Sampled}

The study purposively sampled three national newspapers published in English in Nigeria. These newspapers include: The Guardian, The Nation, and Vanguard. The criteria that guided the selection of these papers include: (1) each is a national daily published in English, (2) each is among the most popular and widely read Nigerian newspapers, (3) each is dedicated to reporting on events and issues unfolding in the country, (4) each is accessible online (Ayodabo, 2013; Mohammed and Rotimi, 2013; Shurudama and Panamah, 2013; Babalola, 2002; Alo and Ogungbe, 2012).

\subsection{The Editorials Sampled}

The study sampled editorials written on social issues only. This decision was informed by findings of earlier studies on contents of editorials in Nigerian newspapers. These studies reported that editorials on social issues were among the most frequent types in the Nigerian newspapers (see Ekeanyanwu, 2009; Uche, 2005). 10 editorial texts were sampled from each of the three newspapers for a period of 6 months -from May to October, 2015. This gave a total of 30 editorial texts of 20,354 words for the analysis.

\subsection{The Collection of Data}

The study data were culled online from the websites of the three newspapers. These papers made available in their websites complete soft copies of all the columns published. Therefore, the editorial texts were all extracted and saved from the papers' websites for the 6 months period. 


\subsection{Analysis Framework}

The study applied Eggin's (2004) lexical cohesion framework in the analyses. The Eggin's framework has been extensively discussed under the Theoretical Framework section (see 1.2 above).

\subsection{Analysis Procedure}

Because the data were sourced from three different newspapers, the analyses began by labelling and coding all the texts. Editorial texts from The Guardian newspaper were labelled GN-01 to GN-10, those from The Nation were labelled NN-01 to NN-10, and those from Vanguard were labelled VN-01 to VN-10. By their nature, the editorial texts handled in the analyses were composed of complete sentences, unlike conversations data where interlocutors might use dependent clauses or even fragments as turns (Taboada, 2004; McCarthy, 1988). Therefore the study segmented each text into sentences and also coded each sentence with number. Moreover, in keeping with Eggins (2004) and also Martin (1992), the present study also recognized both simple and complex lexical content realization. Therefore, lexical units were either made up of single lexical items (simple) or multiple lexical items (complex). Units were also not orthographically restricted. These facts allowed single words, numerals, and multi-word items like word groups and phrasal verbs to serve as potential candidates for cohesive relations.

In this analysis, cohesive relations were analyzed across the sentence boundary (intersententially) as in Halliday and Hasan (1976) and Tanskanen (2006). Therefore, lexical items within the same sentence could not enter into cohesive relations with each other in this analysis. In addition, the analyses adopted the discourse-specific approach in identifying lexical relations. In this approach, lexical relations are not considered fixed because meanings of lexical items are believed to be created and controlled by the contexts. That is why the study did not employ any software in the analyses. The analyses were carefully done manually. The approach was borrowed from previous cohesion analyses such as Gonzalez (2010), McCarthy (1988), and Tanskanen (2006). However, the discourse-specific meanings of items sometimes corresponded to their decontextualized meanings, but this was not a necessary condition. Cohesive units in each sentence were then identified and highlighted.

Finally, the study examined how the lexical cohesive units identified were utilized by the editorialists to build coherence from sentence to sentence, and paragraph to paragraph, throughout the texts. In this attempt, the analysis drew on Gee (2011), Gonzalez (2011) and Tanskanen (2006) by focusing on how the continuity of ideas was supported by the lexical cohesion devices. This was examined at the overall text level (focusing on topical coherence) and also text segment level (focusing on sub-topics). The aim was to discover the typical patterns of lexical cohesion in supporting the editorial texts' coherence.

\section{Results and Discussion}

\subsection{Types and Frequencies of Lexical Cohesion in Newspaper Editorials}

The analysis of the 20,354 words data revealed 2, 685 lexical ties across 849 sentences. The lexical ties were of different types and frequencies. The data analyzed demonstrated that the most frequent types of lexical cohesion in the editorials writing include: repetition $(49.5 \%)$, expectancy relations $(15.8 \%)$, class/sub-class $(11.2 \%)$, and synonymy $(10.8 \%)$. The following table gives a detailed illustration of these findings:

Table 1. Types and Frequencies of Lexical Cohesion

\begin{tabular}{l|c|c|c|c|c|c|c|c}
\hline \multirow{2}{*}{ Lexical Cohesion } & \multicolumn{2}{|c|}{ The Guardian } & \multicolumn{2}{|c|}{ The Nation } & \multicolumn{2}{|c|}{ Vanguard } & \multirow{2}{*}{ Total } & \multirow{2}{*}{$\%$} \\
\cline { 2 - 10 } & $\mathrm{N}$ & $\%$ & $\mathrm{~N}$ & $\%$ & $\mathrm{~N}$ & $\%$ & 73 & 2.8 \\
\hline Co-hyponymy & 44 & 4.4 & 10 & 1.2 & 19 & 2.6 & 73 \\
\hline Class/Sub-class & 141 & 14.3 & 80 & 8.4 & 76 & 10.1 & 297 & 11.2 \\
\hline Contrast & 19 & 2.2 & 26 & 2.7 & 28 & 3.8 & 73 & 2.7 \\
\hline Synonymy & 88 & 9 & 129 & 13.5 & 74 & 9.9 & 291 & 10.8 \\
\hline Repetition & 481 & 48.7 & 478 & 50.2 & 371 & 49.6 & 1,330 & 49.5 \\
\hline Meronymy & 56 & 5.6 & 39 & 4.1 & 36 & 4.8 & 131 & 4.8 \\
\hline Co-Meronymy & 28 & 2.8 & 22 & 2.4 & 14 & 1.9 & 64 & 2.4 \\
\hline $\begin{array}{l}\text { Expectancy } \\
\text { Relations }\end{array}$ & 129 & 13 & 167 & 17.5 & 130 & 17.3 & 426 & 15.8 \\
\hline \multicolumn{1}{c}{ Total } & 986 & 100 & 951 & 100 & 748 & 100 & 2,685 & 100 \\
\hline
\end{tabular}

From table 1 above, it can be understood that some lexical ties are also shown to be relatively infrequent in the editorial genre. These infrequent lexical ties include: co-hyponymy (2.8\%), contrast (2.7\%), meronymy (4.8\%), and co-meronymy $(2.4 \%)$. Therefore, the editorial genre has exhibited repetition, expectancy relations, class/sub-class, and synonymy more than co-hyponymy, contrast, meronymy, and co-meronymy. This preference is more vividly depicted in the figure below: 


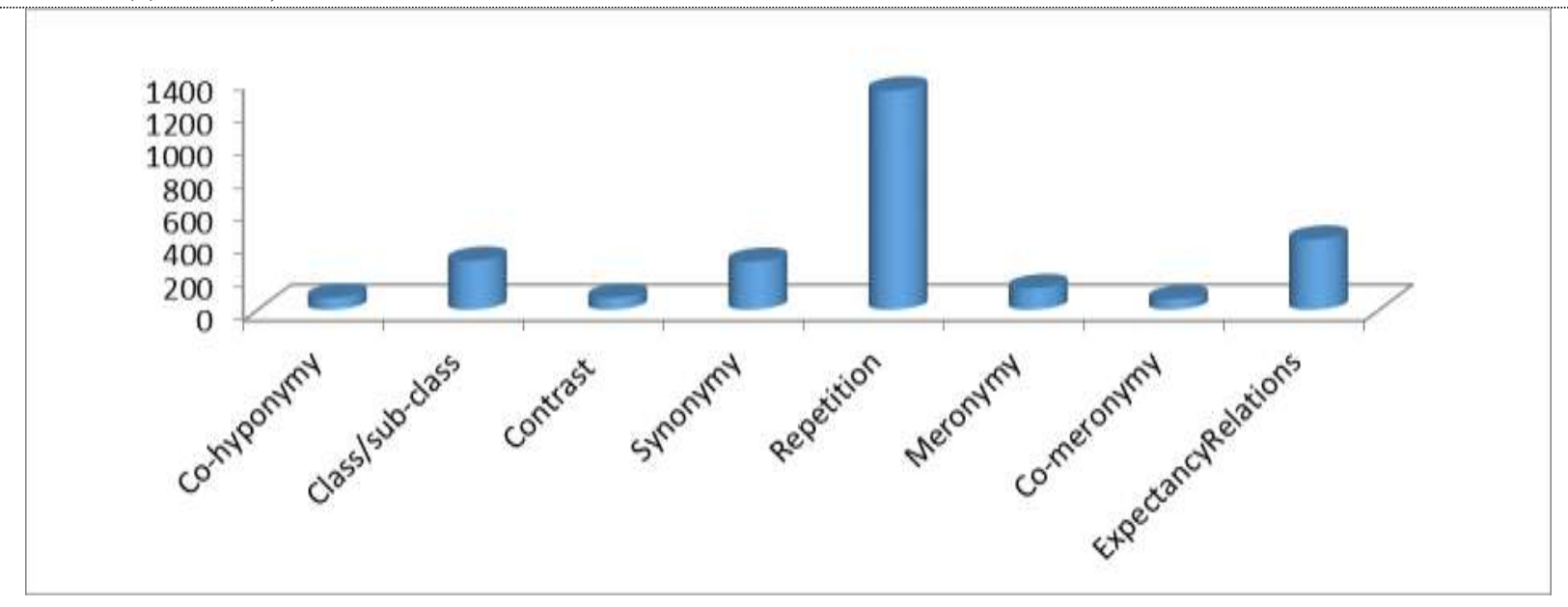

Figure 1. Preference of types of lexical cohesion in newspaper editorials

As seen from figure 1 above, repetition, expectancy relations, class/sub-class, and synonymy are the major sources of lexical cohesion in newspaper editorials. These findings suggest that the editorialists mostly achieve cohesion by reiterating key lexical items, use of lexical items that regularly co-occur, use of items that relate through classification as general to specific, and also use of different items that encode similar contents. For example, VN-10 was written on a tragic incident of forced child marriage involving a teenage girl called Wasila. The innocent girl, out of desperation, resorted to poisoning her groom and some of his friends! In this text, repetition of the lexical item Wasila enables the writer to unify the sentences and consequently manage his topic from the beginning to the end of the essay:

[1]

(1) Wasila Umar regained her freedom: she allegedly killed her husband, his three friends, and injured others... (5) Wasila reportedly poisoned the food she served her husband - she wanted her freedom ... (10) Wasila wanted education; nobody listened to her ... (14) [Police spokesman to journalists]... 'I am assuring you that Wasila would appear in court soon ... we have limitation on the number of days we can keep a suspect ...' (16) Wasila, who confessed to the crime, became dramatic in court ... (20) Those who married off Wasila at 14 broke the law ... (26) Wasila's belated release does not amount to obedience of the law ... (31) Wasila, tragically, gave ... [millions of other endangered children] a voice. (32) We should not wait for another Wasila to free our children.

On the other hand, example 2 below illustrates the use of expectancy relations in the editorial texts. The excerpt is culled from NN-06, which is written on the weird allegations that some important persons in Borno State have been supporting the Boko Haram insurgents when a lot of lives and property are being lost to the deadly activities of the terror champions in the country. The expectancy relations links 7 lexical items in different parts of the text. This device unites the sentences from one part of the text to another. In the text, unpatriotic Borno elders are portrayed as characteristic behavers in unpatriotic ways, and their typical location is Borno State. These elders are said to be characteristic doers of treasonable felony, and it could lead them to suffer capital punishment because of their practice of undermining the army which is criminal conduct:

[2]

(1) ... identify unpatriotic Borno elders sabotaging the campaign against Boko Haram ... (4) ... if they still persist in ... unpatriotic ways, get them to account... (5) ... Nigerian army wishes to inform the public and send a very strong and serious final warning to some prominent individuals ... from Borno State ... on plans ... to undermine and scuttle the fight against terrorism ... (6) ... let us remind them that insurgency or waging war against the country is a treasonable felony ... ... (8) ... the punishment for treason is death, and we wonder how those ... elders can choose to play with such a high offence, that attracts capital punishment ... (9) ... those involved in undermining the army, are also the primary beneficiaries of the war against insurgency ... (19) ... we urge the army to rein in their intelligence, to find out those elders involved in this criminal conduct ...

Nevertheless, example 3 below, from GN-06, illustrates the use of class/sub-class to achieve cohesion in the editorials. Class/sub-class is a relation between a general-class item and its sub-class item(s). In this excerpt, the general-class item facilities relates with the sub-class items: markets, road, parking spaces, and army barracks. This relation has contributed in weaving the sentences together so that the whole text moves as a single unit:

[3]

(1) [It is] disturbing ... [that] ... in Lagos State today ... the bourgeoning population ... has outstripped public facilities ... (3) This is particularly evident in how markets are located ... in the city in awkward locations, constituting a nightmare to the populace. (7) [For instance,] ... users or traders in Ladipo Market offload their trucks on the road ... (14) [The police, however, contribute to 
this because] ... they are pre-occupied with allocating, for a fee, parking spaces to motorists [instead

of maintaining order]... (31) ... like Ladipo... army barracks in Lagos ... are now in city centres ...

Finally, synonymy relation is also employed preponderantly by the editorialists to connect sentences in the editorials. In example 4 below, extracted from $\mathbf{V N - 0 6}$, it can be seen how the synonymy involving the items kidnap, abduction, and taken away is utilized to unify the sentences within a single paragraph.

\section{[4]}

... (5) The recent kidnap of journalists ... attest to this ... (6) ... the most dangerous incident in recent times involved the abduction of Chief Olu Falae... (7) Chief Falae ... was taken away from his farm by criminals ...

Therefore, in an attempt to understand why particular types of lexical cohesion are more preponderant than others in the editorial texts, it could be insightful, perhaps, to have some recourse to the nature of the editorial writing. Editorials have been explained as mostly persuasive and argumentative writings that mostly encode the emotionally charged attitudes of the writers when they are personally involved in the subject matter (Bhatia, 2013; Khabbazi-Oskouei, 2013; Conboy, 2010; Flemming, 2011; So, 2005; Fowler, 1991). Therefore, it could be plausible to understand that these genre-specific features of the editorial texts could have contributed in determining the patterns of lexical cohesion identified in the texts. The most frequent types of lexical cohesion identified in the data could be the most effective in persuasive writings.

However, many previous studies of lexical cohesion in texts of different genres have reported findings that are to some extent consistent with those of the present study. To begin with, in her study of lexical cohesion in different text types, Tanskanen (2006) observed that all the text types analyzed - conversations, prepared speeches, mailing lists, and academic writings - were lexically cohesive; and that reiteration contributed more than collocation in the cohesion of texts. Similarly, the analysis of the present study also revealed that the editorial texts were lexically cohesive, and that repetition contributed more than expectancy relations in the cohesion of editorial texts. Therefore, the two studies have both shown how lexical cohesion contributed to the texture of texts. In her analyses of English and Spanish conversations, Taboada (2004) discovered that although Spanish had higher number of links (620) compared to English (464), repetition (exact) was the most frequent source of lexical cohesion in both English and Spanish conversations. On the other hand, the present study has also arrived at similar findings because repetition (49.8\%) was observed most frequent in the data.

Moreover, Lewin et al.'s (2001) study also discovered that repetition and synonymy were the most dominant types of cohesion in SSR articles. This genre therefore exhibited some cohesive features similar to those of editorials, because the present study also discovered repetition and synonymy among the most dominant sources of lexical cohesion in the editorials. But the present study additionally discovered expectancy relations and class/sub-class among the most frequent types of ties in the editorials. Therefore, while only two types of lexical cohesion were identified the most dominant in SSR articles, four have been discovered in newspaper editorials; and some of which -repetition and synonymy - have been found dominant in the SSR articles. Mirzapour and Ahmad's (2011) study on English and Persian research articles also reported that repetition, collocation, and synonymy were the most frequent types of lexical cohesion in both English and Persian articles. Mirzapour and Ahmad also observed that while English data exhibited the tendency towards repetition and collocation, Persian data exhibited the tendency towards repetition and synonymy. The present study also identified repetition, expectancy relations (which are close to collocation in Halliday and Hasan's 1976), and synonymy as the most frequent types of lexical cohesion in newspaper editorials. But the present study additionally identified class/sub-class (which is close to hyponymy of Halliday and Hasan 1976). Finally, Malah's (2015) study on abstracts of applied linguistics research articles also discovered that repetition (54\%), collocation $(14 \%)$, and hyponymy (11\%) were the most frequent types of lexical cohesion in the study corpus. These findings are therefore consistent with those of the present study, because the present study also identified repetition, expectancy relations, and class/sub-class as the most dominant types of lexical cohesion in newspaper editorials. But the present study's findings slightly differed from Malah's because it additionally identified synonymy among the most frequent types of lexical cohesion.

Therefore, the present study has reported findings that are to some extent consistent with findings of earlier studies of lexical cohesion in texts of different genres, including Hoey (1991) where the scholar argues that repetition is the most basic source of cohesive relationship in texts. Findings of the present study have also pointed to the fact that repetition as a cohesive feature cuts across most texts types.

\subsection{How Lexical Cohesion is Utilized to Build Coherence in the Editorials}

The analysis revealed that lexical cohesion is highly utilized in building coherence of the newspaper editorials. All the editorial texts in the data were lexically cohesive. There were 586 lexical chains and 837 lexical ties in the 849 -sentence corpus analyzed. All the lexical chains and ties discovered were utilized in building meanings in the texts. These patterns of lexical cohesion that support the editorial coherence are graphically illustrated by figure 2 below: 


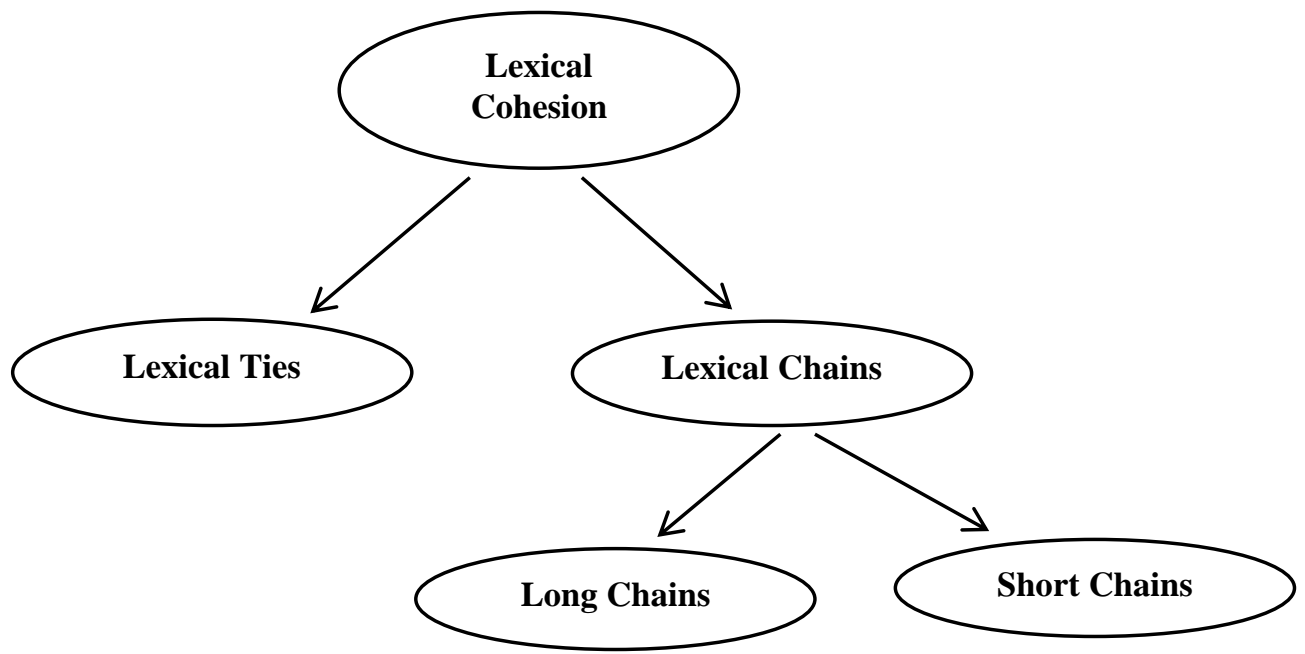

Figure 2. Patterns of Lexical Cohesion in Building Newspaper Editorials Coherence

As seen from figure 2 above, the data analyzed in this study demonstrated that isolated lexical ties, long lexical chains, and short lexical chains interact in building coherence of the newspaper editorials. However, the lexical chains and ties discovered in the editorials worked differently in building coherence in the editorials. In the first place, the lexical chains were of two categories: long lexical chains and short lexical chains. While the long lexical chains, the longest of which had up to 14 links, supported the progression of the general or global topics on which the texts were written, the short lexical chains supported the progression of main ideas on which paragraphs were developed. Moreover, most of the long lexical chains in the data were of three lexical relations: repetition, expectancy relations, and class/sub-class. But the short lexical chains in the corpus were formed from all the lexical relations analyzed in the framework. For instance, the following excerpt illustrates how a long chain of repetition of the item kidnap wove across $\mathbf{G N - 0 4}$ which was written on the phenomenon of kidnap among Nigerians:

[5]

$$
\begin{aligned}
& \text { (1) } \ldots \text { kidnapping ... (5) ... kidnappers } \ldots \text { (8) } \ldots \text { kidnapping } \ldots \text { (10) } \ldots \text { kidnapped } \ldots \text { (11) ... } \\
& \text { kidnapper ... (16) ... kidnapping ... (18) ... kidnapping ... (19) ... kidnappers ... (20) ... kidnapped ... } \\
& \text { (21) ... kidnapped ... (22) ... kidnapped ... (24) ... kidnapped ... (30) ... kidnappers ... (32) ... } \\
& \text { kidnapping ... (35) ... kidnappers ... }
\end{aligned}
$$

Similarly, the following excerpt also illustrates how a short chain of contrast is woven in NN-04 to develop a main topic within the global topic of the text compulsory registration of nomadic herdsmen:

[6] ... (17) ... peace ... (19) ... conflicts ... (20) ... clashes ... (24) ... troubles ...

On the other hand, a lexical tie is a relation between only a pair of lexical items. The ties in discovered in the data behaved like the short chains because they were used in linking sentences mostly within paragraphs, and rarely across paragraphs. But unlike the short chains, the ties could of course link only pairs of sentences. They contributed in the propositional development from sentence to sentence. Like the short chains lexical chains, the ties in the corpus were formed from all the types of lexical relations analyzed in the study. The following excerpt, for example, shows a lexical tie of meronymy from $\mathbf{V N - 0 8}$ of the data:

[7] (1) ... Nigeria ... (2) ... Ekiti State ...

Therefore, the findings of this study are corroborated by findings of many cohesion studies (see, for instance, Gonzalez, 2011; Gonzalez, 2010; Tanskanen, 2006; Taboada, 2004; Hoey, 1991; Morris and Hirst, 1991; Parsons, 1990; Ventola, 1987). These studies have all discovered that cohesive chains and ties contribute to the coherence of their data. In her analysis of spoken and written monologues and dialogues, Tanskanen (2006) has discovered how communicators utilized short lexical chains, long lexical chains, and isolated ties in collaborating towards coherence. Taboada's (2004) study of English and Spanish conversations reported that cohesive chains (major and minor) are interactively built by interlocutors to achieve coherence, and that major chains are capable of distinguishing between single-topic and multitopic conversations. Gonzalez (2011) and Gonzalez (2010) have both shown how interlocutors in broadcast discussions and telephone conversations, respectively, utilized lexical chains to achieve coherence. Morris and Hirst (1991), Parsons (1990), and Ventola (1987) have all discovered that lexical chains are capable of marking topical segments in discourse, that long lexical chains are the most powerful for texts' coherence, and that lexical cohesion can indicate the fields of texts by showing related items. Therefore, the findings of the present study are consistent with those of many cohesion studies.

\subsubsection{How Long Lexical Chains Build Coherence in the Editorials}

The long chains were woven across the lengths of most of the texts in the data to support the continuity of the global topics. This resulted in smooth propositional development across the texts. The chains corresponded to the progression of the global topics because they were related to the topics, and they wove from the first paragraph to the last. In addition, as earlier highlighted, these chains were generally of three types of lexical relations: repetition, expectancy 
relations, and class/sub-class. The following excerpt illustrates how a long chain of repetition of Ekiti State supported the general topic in VN-08:

[8]

(1) ... we would think Ekiti State was without ... security agencies ... (2) ... statements from the authorities in Ekiti State underline empty efforts to halt a ... decline in the State's security... (6) ... in Ekiti State, we can assume security operations ... are below average ... (8) Are we to assume that laws Ekiti State inherited ... and the ones that its legislators have been making ... are inadequate to deal with the criminals who have taken over the State? (11) ... security agencies in ... for their efforts in ensuring peace in Ekiti. (20) Why is Ekiti the choice location for ... serial crimes? (21) The security agencies are ... already being praised for "ensuring peace" in Ekiti... (23) Ekiti needs help ... (24) ... Ekiti could be a practising ground for future criminals. (25) If criminals ... prosper in Ekiti, the State would soon be too small to accommodate their big dreams...

The parent text of the above excerpt was written on how Ekiti State was bedeviled by criminal activities. The long chain of repetition of Ekiti State or Ekiti, which has 9 links, has run from the first sentence to the last paragraph to support the continuity of the topic. The chain has enabled the writer to develop the idea smoothly throughout the text, because the constant repetition of the item constructs this overall coherence in the text.

On the other hand, a long chain of class/sub-class is also evidenced below from GN-01. The text was written on the phenomenon of child abuse which had become rampant among Nigerians. The chain has 6 links as follows:

[9]

(1) ... the gravity and magnitude of the horrific incidents of child abuse ... should be food for thought ... (3) ... no day passed without reportage of rape cases ... (4) Of equal frequency was ... corporal punishment ... as fathers turn their homes into torture chambers ... (15) ... the use of extreme punishment ... is neither ... any means of reforming or correcting a child ... (21) ... maltreatment of children ... destroys quality parent-child relationship ... (24) ... infliction of injury are likely to negatively affect the cognitive function of the child ... (32) Parents, guardians and care-givers should be made to understand that ... violent approaches to child training amount to abuse.

In this excerpt, child abuse is the superordinate term that relates to the other lexical items in a class/sub-class relation. In this particular context, the writer means that all the other lexical items are types of child abuse. These types of child abuse include rape cases, corporal punishment, extreme punishment, maltreatment of children, infliction of injury, and violent approaches to child training. This chain has therefore contributed in constructing the whole coherence of the text by enabling the writer to relate different paragraphs of the essay on the global topic of child abuse.

A long chain of expectancy relations is also shown below from $\mathbf{N N - 0 3 . ~ T h e ~ t e x t ~ w a s ~ w r i t t e n ~ i n ~ a ~ c o n c e r n e d ~ t o n e ~ o n ~}$ how groups of hoodlums re-surfaced and kept troubling the Lagos City residents. The excerpt runs:

[10]

... (2) ... Lagos was a city as model for gangster robbers ... (3) ... they raided banks, markets and homes of the well-heeled ... (6) They shot into the air ... (7) They operated for as long as they wanted ... (11) They do harm. (12) ... They threaten, steal, rob, maim, and introduce what was once a history to the profile of the city's crime ... (17) The bad boys are ... clever and imaginative in their devilry ... (35) The commissioner of police has started to step up police presence in ... major places of horror, especially the Third Mainland Bridge ...

In this expectancy chain, the lexical item gangster robbers relates to all the other items in the chain. It is mentioned first in the chain, and the lexical item encodes the characteristic doers of all the actions encoded in the excerpt. The gangster robbers characteristically raided, shot, operated, harm, threaten, steal, rob, and maim. They were also the characteristic doers of devilry, and their typical location was the Third Mainland Bridge. This chain of related items has contributed in building the text's coherence.

\subsubsection{How short Lexical Chains Build Coherence in the Editorials}

The short lexical chains, unlike the long chains, were used to hold shorter stretches of texts together. They were found within paragraphs, and also across smaller number of paragraphs compared to the long chains. The following excerpt from GN-10 illustrates a short chain of synonymy:

[11]

(1) ... there is the urgent need for the government ... to stop this alarming carnage on Nigerian roads.

(2) ... this tragedy happened in Onitsha ... (6) The nation has had enough of such ... accidents ...

The text was written in a critical tone on the reckless attitudes of some young fuel trucks drivers that often resulted in infernos causing avoidable loss of lives in Nigeria. The writer has utilized this short chain of synonymy involving carnage, tragedy, and accidents to achieve coherence.

A short chain of co-meronymy is also shown in the following excerpt from $\mathbf{V N - 0 3}$. The global topic of the parent text is why kidnappers operated unhindered in some parts of Nigeria. The writer sounded critical of the Nigerian security agencies. The chain is composed of co-parts of Nigeria as follows: 
[12]

(1) ... Oyo State ... made the map last year when police ... uncovered a den of kidnappers there ... (11) The building was demolished ... a practice ... etched into the law in Anambra State to deal with kidnapping ... (14) It was ... the case ... in parts of Ogun State this month. (15) There have been similar incidents in Lagos ...

The short meronymy chain in the excerpt involves Oyo State, Anambra State, Ogun State, and Lagos. These are all parts of Nigeria. Therefore, this chain has been utilized by the writer in relating different parts of the text and this has contributed to the coherence of the text.

A short chain of co-hyponymy is also shown below from NN-10 of the corpus. The parent text was written on an incident of deaths in a Nigerian community after people consumed locally made and unregistered alcoholic drinks. The chain in this excerpt connects instances of measures taken by the Nigerian authorities to curb the menace:

(1) Public enlightenment ... will help in the circumstance ... (10) ... law enforcement agencies have ... to enforce the ban on alcoholic drinks ... (22) ... conduct further investigation into the deaths

In this excerpt, a short chain of related items public enlightenment, ban, and investigation has been utilized by the writer in achieving the text's coherence. This is how short chains of different lexical relations were utilized by the editors in making meanings in the newspaper editorials.

\subsubsection{How Lexical Ties Build Coherence in the Editorials}

The analysis of this study revealed 837 lexical ties across sentence boundaries. These ties were discovered to have been utilized in connecting pairs of sentences either within the same paragraphs or from different paragraphs. They were also of different lexical relations. In addition, the analysis further revealed that these ties were also used as resources for constructing coherence in the editorial texts. The following excerpt, for instance, shows some ties of contrast relation from NN-07 of the corpus:

... (11) ... We have a huge children population and ... this category ... is most vulnerable to road crashes. (12) ... there is the need to make them safe ...

The excerpt was culled from a text written to compassionately discuss how great number of children was being lost as a result of road accidents in Nigeria. The contrast relation between vulnerable in sentence 11 and safe in sentence 12 provides some cohesive force that has ultimately contributed in the coherence of the text.

Likewise, another excerpt is also given below from $\mathbf{V N - 0 4}$ of the corpus to illustrate instances of ties of repetition. The parent text of the excerpt was written on the plan by Governor El-Rufa'i to ban street begging and hawking in Kaduna State and the response of the beggars. The excerpt reads:

(1) KADUNA State Governor ... drew the ire of beggars ... when he threatened to pull them off the streets. (2) The beggars, in return, threatened to pull down his government for daring to send them out of "business"...

In this excerpt, two instances of repetitions are identified. The items beggars/threatened from sentence 1 have both been repeated in sentence 2 . This cohesive relation has resulted in flow of the idea from the first sentence to the second, and has consequently contributed in the meaning made in the paragraph.

From GN-07 of the corpus, instances of class/sub-class ties are also illustrated in the excerpt below. The text was written to admonish the Nigerian public to act in accordance with the flood warning just issued by the government:

(1) ... early warning is critical to the management of natural disasters ... (3) ... The flood waters ... will affect all communities on the banks of the River Benue and the River Niger down to the Niger Delta area ... (7) ... the Lagdo dam would be released anytime between now and November. (8) ... this might coincide with the second rainfall peak that should occur this month ...

In this excerpt, two class/sub-class ties are identified. The first tie is between natural disasters of sentence 1 and flood waters in sentence 3. This means that flood waters are types of natural disasters. The second tie is between November in sentence 7 and month in sentence 8 . This means that November is a type of month. This cohesive force has impacted on the coherence built in the text by relating the sentences. These evidences have shown how lexical ties of various lexical relations have also contributed in constructing coherence of the editorial texts.

Therefore, the analyses of this study have revealed the pattern of lexical cohesion in newspaper editorials, and also how lexical cohesion is utilized in building coherence in the editorial texts. It has been understood that the editorialists utilized long lexical chains, short lexical chains, and simple ties in constructing meanings. Accordingly, it has been evidenced how the long lexical chains, which wove across the spans of most texts, were utilized in building global topics in the texts; how the short lexical chains, which were mostly woven within paragraphs or shorter stretches of 
texts, related to sub-topics (or main ideas) developed in paragraphs; and how simple ties were used in connecting pairs of sentences either within or across paragraphs. The lexical chains have therefore been observed to always support the continuity of topics in the texts.

However, from the foregoing illustrations, it would be understood that the findings of the present study are corroborated by findings of many previous cohesion studies (see, for instance, Gonzalez, 2011; Gonzalez, 2010; Tanskanen, 2006; Taboada, 2004; Martin, 1992; Hoey, 1991; Morris and Hirst, 1991; Parsons, 1990; Ventola, 1987; Hasan, 1984). These studies have all shown how cohesive ties and chains contributed to the coherence of different text types. To begin with a study concerned with both spoken and written texts, Tanskanen (2006: 104-158) reported that communicators utilized lexical cohesion to collaborate towards coherence. The patterns of lexical cohesion that emerged from Tanskanen's analysis include: isolated pairs, long chains, and shorter chains. These patterns contributed to the coherence of all the texts types investigated - spoken dialogues, written dialogues, written monologues (academic writing), and spoken monologues (prepared speeches). On the specific patterns of lexical cohesion in each of the genres explored, Tanskanen (2006) further observed that although similar patterns cut across all the text types, conversations had lower number of long chains than (written or spoken) monologues. The researcher contends that while long chains, as in conversation 1 and 3 in the data, were rare in the conversations, shorter chains, as in conversation 2 and 4, were preponderant because interlocutors mostly shifted topics and chains were accordingly initiated, discussed, and abandoned (see Tanskanen, 2006:104-111). Therefore, the study reported that few conversations, such as 1 and 3, contained long chains because they were single-topic, where interlocutors concentrated on single topics; and most conversations, such as 2 and 4, contained several short chains because interlocutors shifted multiple topics.

Similarly, other studies that focused on spoken data, such as Gonzalez (2011) on multiparty broadcast discussions, Gonzalez (2010) on telephone conversations, Taboada's (2004) on English and Spanish conversations, have similarly shown how interlocutors collaboratively built cohesive ties and chains both across and within speaker turns to achieve coherence in (both single-topic and multi-topic) dialogues. Taboada reported that each conversation in her data had an average of 4 chains, where Spanish data exhibited longer chains than those in English. She showed how cohesive ties (what Tanskanen refers to as isolated pairs), major chains (what Tanskanen refers to as long chains), and minor chains (what Tanskanen refers to as short chains), contributed to the coherence of the conversations. Taboada illustrated how interlocutors interactively created, discussed, and abandoned cohesive chains on the initiation of new ones, as strategies for building coherence.

To return to the monologues side of Tanskanen's (2006) study, it has been reported that the spoken and written monologues shared cohesive patterns that suggested that these text types were mainly single-topic. The study discovered that, in addition to isolated pairs, monologues mostly contained long chains and several shorter chains that support the progression of thought in textual segments. The long chains were reported to have run through the texts and consequently provided the texts' topical coherence, while the shorter chains indicated textual segments. This is similar to what the present study has discovered in the editorial texts, which are also forms of monologic texts that mostly concentrate on single topics. In the editorials too, the long chains that run across the length of the texts have been understood as the most powerful in building the texts' coherence. In similar studies, Parsons (1990) and Ventola (1987) have also shown how long lexical chains contributed to the coherence of non-narrative texts, and how they were capable of indicating the fields of texts by showing related lexical items. Moreover, in her analysis of children's narratives, Hasan (1984) has also reported how interaction of cohesive chains that resulted in cohesive harmony consequently led to the coherence of texts.

Therefore, the findings of the present study are to some extent consistent with findings of previous lexical cohesion studies on different genres. Each of these studies has reported how lexical cohesion contributes to the coherence of the different text types being investigated. They have also discovered how lexical chains build coherence in texts by corresponding to topic progression in the texts. However, the present study has additionally discovered the related but different roles of long and short lexical chains interacting in the editorial texts. In this interaction, the long chains have been discovered more related to global topics, while the short chains and isolated ties are also more related to sub-topics that are developed at text segments.

\subsection{Pedagogical Implications}

Applied linguistic researches are often conducted so that the findings could be utilized to enhance how languages (in use) are understood, interpreted and used. This would also improve the quality of practice of the linguistic discipline (Merriam \& Tisdell, 2015). In a relevant discussion, Bhatia (2013) argues that exploitation of newspaper English would have pedagogical applicability in three major areas of language learning: EGP, EAP, and ESP. The scholar elucidates that the different newspaper genres represent different types of English in accordance with the different communicative purposes they serve. Similarly, So (2005) also claims that analyzing newspaper genres could lead to findings that would bring about improvement in writing school genres, far beyond how typical composition instruction could do. This is because, as Flowerdew (2015) also concedes, corpus-informed pedagogy would helpfully have potential classroom applications especially in ESP and EAP. Interestingly, some newspaper genres and school genres have shared conventions and overlaps. For instance, the newspaper editorials and school argumentative essays are both persuasive in nature. The two share persuasive features where writers consciously structure texts in order to create a bond between them and the readers (Khabbzi-Oskouei, 2013). In addition, this close relation between the two genres would allow successful transferability of genre knowledge from one to another (So, 2005). Therefore, similar to the suggestions 
made by other researchers who have similarly explored newspaper genres (see, for example, Ansary and Babaii, 2005; So, 2005; Yin, 2005), the present study could also be beneficial in the contexts of EGP, ESP, and EAP.

Specifically, the present study could benefit learners, teachers, and also contribute some input in material or syllabus development especially in the areas of persuasive (journalistic) writing and also in general writing skills. The study has focused on the lexical aspect of writing, which has been argued to be the most contributing in the texture of texts (Hoey, 1991; Mohamed-Sayidina, 2010), and which has recently claimed more attention in language teaching (Henry and Roseberry, 2007). The study has reported the patterns of lexical cohesion preferred in writing newspaper editorials, and how these patterns are utilized in building meanings in the texts. It has been reported that the major types of lexical cohesion in the editorials include repetition (49.5\%), expectancy relations (15.8\%), class/sub-class $(11.2 \%)$, and synonymy $(10.8 \%)$. It has also been shown how the editorial coherence is achieved through the use of lexical cohesion devices that relate in networks of long and short chains which relate to general topics and sub-topics respectively, or simple ties that connect sentences.

Therefore, while being trained on how to write editorials, or being taught how to enact persuasive discourses, or preparing materials for related persuasive writings, the findings of the present study could be sensitizing on how lexical items are patterned in these types of writings.

\section{Conclusion}

This study focused only on Nigerian newspapers written in English, future studies could interestingly compare lexical cohesion across different languages to reveal how cultural differences could be reflected in the lexical cohesion patterns. In addition, scholarly attention may also be focused on comparing lexical cohesion in various newspaper genres to explore how their different communicative purposes determine the patterns of lexis. Ultimately, the findings of the study, and of course those of the recommended future studies, could benefit learners in writing school genres.

\section{References}

Ademilokun, M, \& Taiwo, R. (2013). Discursive strategies in newspaper campaign advertisements for Nigeria's 2011elections. Discourse \& Communication, 7(4), 435-455.

Angermeyer, P. S. (2002). Lexical cohesion in multilingual conversations. International journal of Bilingualism, 6(4), 361-393.

Ansary, H., \& Babaii, E. (2005). The Generic Integrity of Newspaper Editorials: A Systemic Functional Perspective. RELC Journal, 36(3), 271-295.

Ansary, H., \& Babaii, E. (2009). A Cross-cultural Analysis of English Newspaper Editorials : A Systemic-Functional View of Text for Contrastive Rhetoric Research. RELC Journal, 40(2), 211-249.

Alo, M., \& Ogungbe, E. O. (2012). Lexicalisation in news stories of some Nigerian national newspapers. lumina.hnu.edu.ph

Babalola, E. T. (2002). Newspapers as instruments for building literate communities: The Nigerian experience. Nordic Journal of African Studies, 11(3), 403-410.

Baker, P., \& Ellece, S. (2011). Key terms in discourse analysis. A\&C Black.

Bhatia, V. K. (2014). Analysing genre: Language use in professional settings. London/Newyork: Routledge.

Bhatia, V. (2004). Worlds of written discourse: A genre-based view. A\&C Black.

Björklund, M. (1993). Narrative Strategies in Chechov's 'The Steppe': Cohesion, Grounding and Point of View. Åbo: Åbo Akademi University Press.

Blakemore, D. (1992). Understanding utterances: An introduction to pragmatics (pp. 155-78). Oxford: Blackwell.

Blommaert, J. (2005). Discourse: A critical introduction. Cambridge University Press.

Bloor, T., \& Bloor, M. (2004). The functional analysis of English. London: Arnold

Bodunde, H. A., \& Sotiloye, B. S. (2013). A Critique of Undergraduate Students' Writing Skill in an ESL Setting: Samples from the Federal University of Agriculture, Abeokuta, Nigeria. World Journal of English Language, 3(2), 10.

Bolivar, A. (1994). The structure of newspaper editorials. Advances in written text analysis, ed. by Malcom Coulthard, 276-294.

Bonyadi, A., \& Samuel, M. (2013). Headlines in newspaper editorials: A contrastive study. Sage Open, 3(2), 1-10.

Bloor, T., \& Bloor, M. (2004). The functional analysis of English. Routledge.

Brown, H. D. (2014). Principles of Language Learning and Teaching: A Course in Second Language Acquisition. Pearson Education.

Brown, G., \& Yule, G. (1983). Discourse analysis. Cambridge University Press.

Carter, R. (2001). Working with texts: a core introduction to language analysis. Psychology Press.

Carter, R., \& McCarthy, M. (1988). Vocabulary and language teaching. Routledge. 
Castro, C. D. (2004). Cohesion and the social construction of meaning in the essays of Filipino college students writing in L2 English. Asia Pacific Education Review, 5(2), 215-225.

Childs, P., \& Fowler, R. (Eds.). (2006). The Routledge dictionary of literary terms. Routledge.

Conboy, M. (2010). The language of newspapers: Socio-historical perspectives. Bloomsbury Publishing.

Creswell, J. W. (2012). Educafion research: planning, conducting and evaluating quantitative and qualitative research. Boston/New York: Pearson

Daze, B. D., \& Ebibi, J. O. (2014). Effect of Process Approach to Writing on Senior Secondary Students' Achievement in Writing (Plateau Central Senatorial District). AFRREV IJAH: An International Journal of Arts and Humanities, 3(4), 47-59.

De Beaugrande, R. \& Dressler, W. (1981). Introduction to text linguistics. London: Longman

Dörnyei, Z. (2007). Research methods in applied linguistics: Quantitative, qualitative, and mixed methodologies. Oxford University Press.

Eggins, S. (2004). Introduction to systemic functional linguistics. A\&C Black.

Ekeanyanwu, N. T. (2009). Analysis of the Content of Nigeria's Newspaper Editorials. Oko Journal of Communication \& Information Science, 1(2), 74-103.

Enkvist, N. E. (1978). Coherence, Pseudo-Coherence, and Non-Coherence

Fairclough, N. (1995). Media discourses. London: Edward Arnold.

Fetzer, A. (2004). Recontextualizing context: Grammaticality meets appropriateness. John Benjamins Publishing.

Fowler, R. (1991). Language in the News: Discourse and Ideology in the Press. London and New York: Routledge.

Flowerdew, J. (2013). Discourse in English language education. Routledge.

Flowerdew, J. (2015). John Swales's approach to pedagogy in Genre Analysis: A perspective from 25 years on. Journal of English for Academic Purposes, 19, 102-112.

Gee, J. P. (2011). How to do discourse analysis: A toolkit. Routledge.

Gee, J. P. (2011). An introduction to discourse analysis: Theory and method. Routledge.

González, M. D. L. Á. G. (2010). Evaluating lexical cohesion in telephone conversations. Discourse Studies, 12(5), 599-623.

González, M. D. L. Á. G. (2011). Lexical cohesion in multiparty conversations. Language Sciences, 33(1), 167-179.

Gutwinski, W. (1976). Cohesion in literary texts: a study of some grammatical and lexical features of English discourse (Vol. 204). Walter de Gruyter.

Halliday, M. A. (1994). Functional grammar. London: Edward Arnold.

Halliday, M. A., \& Matthiessen, C. M. (2014). Halliday's introduction to functional grammar. Routledge.

Halliday, M. A. K., \& Hasan, R. (1976). Cohesion in English. Routledge.

Hameed, H. T. (2008). Cohesion in Texts: A Discourse Analysis of a News Article in a Magazine. Al-Faith Journal. No 37, pp. 81-144

Hasan, R. (1984). Coherence and cohesive harmony. Understanding reading comprehension: Cognition, language and the structure of prose, 181-219.

Haswell, R. H. (1988). Critique: Length of text and the measurement of cohesion. Research in the Teaching of English, 428-433.

Henry, A., \& Roseberry, R. L. (2007). Language errors in the genre-based writing of advanced academic ESL students. RELC Journal, 38(2), 171-198.

Hoey, M. (2005). Lexical priming: A new theory of words and language. Psychology Press.

Hoey, M. (2001). Textual interaction: An introduction to written discourse analysis. Psychology Press.

Hoey, M. (1991). Patterns of lexis in text.

Hyland, K. (2003). Second language writing. Ernst Klett Sprachen.

Hyland, K. (2009). Teaching and researching writing. Routledge.

Jabeen, I., Faiz, R., Mehmood, A., \& Yousaf, N. (2013). Cohesion and Semantic Understanding. Academic Research International, 4(6), 139.

Jones, R. H. (2012). Discourse analysis. London and New York: Routledge.

Kane, T. S. (2000). Oxford essential guide to writing. Berkey Publishing Group.

Kaplan, R. B., \& Grabe, W. (2002). A modern history of written discourse analysis. Journal of second language writing, 11(3), 191-223. 
Khabbazi-Oskouei, L. (2013). Propositional or non-propositional, that is the question: A new approach to analyzing 'interpersonal metadiscourse'in editorials. Journal of Pragmatics, 47(1), 93-107.

Kolin, P. (2013). Successful writing at work. (10 ${ }^{\text {th }}$ eds) Boston: Wadsworth

Kolin, P. (2009). Successful writing at work. (4th eds) Cengage Learning.

Kuhi, D., \& Mojood, M. (2014). Metadiscourse in Newspaper Genre: A Cross-linguistic Study of English and Persian Editorials. Procedia-Social and Behavioral Sciences, 98, 1046-1055.

Le, E. (2009). Editorials' genre and media roles: Le Monde's editorials from 1999 to 2001. Journal of Pragmatics, 41(9), 1727-1748.

Lewin, B., Fine, J., \& Young, L. (2001). Expository discourse. A\&C Black.

Liu, M., \& Braine, G. (2005). Cohesive features in argumentative writing produced by Chinese undergraduates. System, 33(4), 623-636.

Lyons, J. (2002). Language and linguistics. Cambridge University Press.

Maddalena, A., \& Belmonte, I. A. (2011). Unveiling the writer-reader interaction in Peninsular Spanish and American English newspaper editorials: A cross linguistic study. Journal of Pragmatics, 43(3), 891-903.

Malah, Z. (2015). Lexical Cohesion in Academic Discourse: Exploring Applied Linguistics Research Articles Abstracts. Research Journal of English Language and Literature,3(4), 291-299.

Martin, J. R. (2001). Cohesion and Texture. The Hand Book of Discourse Analysis.

Martin, J. R. (1992). English text: System and structure. John Benjamins Publishing.

Matthiessen, C., Teruya, K., \& Lam, M. (2010). Key terms in systemic functional linguistics. A\&C Black.

Matthews, B., \& Ross, L. (2010). Research methods. Pearson Higher Ed.

Mayor, M. (2009). Longman dictionary of contemporary English. Pearson Education India.

McCarthy, M. (1991). Discourse analysis for language teachers. Cambridge University Press.

Merriam, S. B., \& Tisdell, E. J. (2015). Qualitative research: A guide to design and implementation. John Wiley \& Sons.

Meyer, C. F., Halliday, M. A. K., \& Hasan, R. (1987). Language, Context, and Text: Aspects of Language in a Social-Semiotic Perspective.

Mikics, D. (2007). A new handbook of literary terms. Yale University Press.

Mirzapour, F., \& Ahmadi, M. (2011). Study on lexical cohesion in English and Persian research articles (A Comparative Study). English Language Teaching, 4(4), 245.a

Mohamed-Sayidina, A. (2010). Transfer of L1 cohesive devices and transition words into L2 academic texts: The case of Arab students. RELC Journal, 41(3), 253-266.

Morris, J., \& Hirst, G. (1991). Lexical cohesion computed by thesaural relations as an indicator of the structure of text. Computational linguistics, 17(1), 21-48.

O'keeffe, A. N. N. E. (2006). Investigating media discourse. Routledge.

Olatunde, A. J. (2013). The Dynamics of The Language of Newspaper Headlines in Nigeria. International Journal of Applied Linguistics and English Literature, 2(5), 139-144.

Olofin, A. O. (2013). Effects Of Bilingualism On The Essays Of Yoruba/English Bilinguals. European Journal of Arts and Humanities Vol, 1(1).

Onyebadi, U. (2005). Nigeria's private media and agenda setting: An evaluation of This day newspaper's house editorials (2004) (Doctoral dissertation, University of Missouri--Columbia).

Parsons, G. (1990). Cohesion and Coherence: Scientific Texts (A Comparative Study) [Monographs in Systemic Linguistics 1]. Nottingham: University of Nottingham, Department of English Studies.

Peck, J., \& Coyle, M. (1984). Literary terms and criticism: a student's guide. Macmillan Pub Ltd.

Rahman, Z. A. A. A. (2013). The Use of Cohesive Devices in Descriptive Writing by Omani Student-Teachers. SAGE Open, 3(4), 2158244013506715.

Reah, D. (2002). The Language of Newspapers. London and New York: Routledge

Rundell, M., \& Fox, G. (Eds.). (2007). Macmillan English dictionary for advanced learners.

Sanders, T., \& Maat, H. P. (2006). Cohesion and coherence: Linguistic approaches. Reading, 99, 440-466.

Sani, I., Abdullah, M. H., Ali, A. M., \& Abdullah, F. S. (2012). Linguistic analysis on the construction of satire in Nigerian political cartoons: The example of newspaper cartoons. Journal of Media and Communication Studies, 4(3), 52.

Schiffrin, D., Tannen, D., \& Hamilton, H. E. (Eds.). (2008). The handbook of discourse analysis. John Wiley \& Sons. 
Sharndama, E. C., \& Panamah, J. H. (2013) Thematic Structure and Progression in Selected Business News Reports of Two Nigerian Newspapers: Implications for Professional Writing. Journal of Arts and Humanities, 2(7)

So, B. P. (2005). From analysis to pedagogic applications: Using newspaper genres to write school genres. Journal of English for Academic Purposes, 4(1), 67-82.

Sperber, D., Wilson, D. (1986). Relevance: Communication and cognition (Vol. 142). Cambridge, MA: Harvard University Press.

Sperber, D., Wilson, D. (2006) in (Eds.). Horn, L., \& Ward, G. The handbook of pragmatics (Vol. 26). John Wiley \& Sons.

Stubbs, M. (2001). Computer-assisted Text and Corpus Analysis: Lexical Cohesion and Communicative Competence. The handbook of discourse analysis, 18, 304.

Swales, J. (1990). Genre analysis: English in academic and research settings. Cambridge University Press.

Taboada, M. T. (2004). Building coherence and cohesion: Task-oriented dialogue in English and Spanish (Vol. 129). John Benjamins Publishing.

Talbot, M. (2007). Media discourse: Representation and interaction. Edinburgh University Press.

Tanskanen, S. K. (2006). Collaborating towards coherence: Lexical cohesion in English discourse (Vol. 146). John Benjamins Publishing.

Tavakoli, H. (2010). A dictionary of research methodology and statistics in applied linguistics. Rahnama press.

Van Dijk, T. A. (2008). Discourse and context. A sociocognitive approach. Cambridge.

Van Dijk, T. A. (1997). Discourse as social interaction (Vol. 2). Sage.

Ventola, E. (1987). The structure of social interaction: A systemic approach to the semiotics of service encounters. Pinter Pub Ltd.

Widdowson, H. G. (2004). Text, context, pretext. Malden/Oxford: Blackwell Publishing.

Widdowson, H. G. (1978). Teaching language as communication. Oxford University Press.

Wu, S. (2010). Lexical cohesion in oral English. Journal of Language Teaching and Research, 1(1), 97-101.

Wyrick, J. (2011). Steps to writing well with additional readings. ( $8^{\text {th }}$ eds) Boston: WADSWORTH Cengage Learning. Yule, G. (2014). The study of language. Cambridge University Press.

Yin, Z. (2015). The Use of Cohesive Devices in News Language: Overuse, Underuse or Misuse?. RELC Journal, 46(3), 309-326. 